\title{
Progress in Research on Post-Traumatic Stress Disorder*
}

\author{
Ning Bei' ${ }^{1}$ Dengyi Long ${ }^{1}$, Juncheng Guo ${ }^{2}$, Xiangling Jiang# \\ ${ }^{1}$ Hainan Provincial Cadre Sanatorium (Hainan Geriatric Hospital), Haikou, China \\ ${ }^{2}$ Xiangya School of Medicine Affiliated Haikou Hospital, Central South University, Haikou, China \\ ${ }^{3}$ Department of Psychology, Hainan General Hospital, Haikou, China \\ Email: "g2002m@163.com, 472794266@qq.com
}

How to cite this paper: Bei, N., Long, D.Y., Guo, J.C. and Jiang, X.L. (2019) Progress in Research on Post-Traumatic Stress Disorder. Journal of Behavioral and Brain Science, 9, 26-32.

https://doi.org/10.4236/jbbs.2019.92003

Received: January 16, 2019

Accepted: February 12, 2019

Published: February 15, 2019

Copyright $\odot 2019$ by author(s) and Scientific Research Publishing Inc. This work is licensed under the Creative Commons Attribution International License (CC BY 4.0).

http://creativecommons.org/licenses/by/4.0/

\begin{abstract}
In recent years, with the increase of natural disasters, wars, and terrorist incidents, etc., there are more and more researches on post-traumatic stress disorder (PTSD). This paper bases on the definition, pathogenic mechanism and related gene research of post-traumatic stress disorder. Mechanism, reviews the research status of post-traumatic stress disorder to improve people's understanding of post-traumatic stress disorder, and prospect for future research.
\end{abstract}

\section{Keywords}

Post-Traumatic, Stress Disorder, DRD2, PTSD

\section{Definition of PTSD}

Since the concept of post-traumatic stress disorder (PTSD) was formally proposed, its definition has been revised for three times. In 1980, the third edition of the Diagnostic and Statistical Manual of Mental Disorders (DSM-III) first proposed post-traumatic stress disorder, described as a psychiatric symptom caused by exposure to traumatic events beyond normal humans [1]. During the Second World War, people further realized that the "cannonball shock" neurosis can occur in a wide range. In 2000, the definition of post-traumatic stress disorder in the Fourth Edition of the Diagnostic and Statistical Manual of Mental Disorders (DSM-IV) was updated as experiencing unusual threatening or catastrophic stress events (situations) leading to delayed emergence and Long-standing men-

*Supported by Hainan Provincial Natural Science Foundation of China (No. 818MS163) and Hainan Provincial Key Research and Development Program (No. ZDYF2018227). 
tal disorders [2]. Compared to the third edition, this definition complements the time characteristics of PTSD. PTSD usually occurs after several days, weeks, or even months of trauma, and the duration of symptoms varies from patient to patient, ranging from one month to several years. In addition, the manual also pointed out the three core symptoms of PTSD: recurrence of traumatic experience, persistent avoidance and increased levels of persistent alertness; in 2013, the Fifth edition of the Diagnostic and Statistical Manual of Mental Disorders (DSM-V) remains the definition of PTSD unchanged, but the core symptoms of "cognitive and mood-related negative changes associated with traumatic events" have been added. As a result, the symptoms of PTSD have changed from three core symptoms to four core symptoms [3]. Through more than 30 years of PTSD definition changes, along with the social development, people's understanding of post-traumatic stress disorder is getting deeper and deeper.

\section{Pathogenic Mechanism of PTSD}

Traumatic event is a necessary condition for the diagnosis of PTSD, but not sufficient conditions for PTSD's production. Although most people suffer symptoms in different degrees after a traumatic event, studies have shown that only some people eventually become PTSD patients. At present, the mechanism of its production includes the following aspects: the study of the influence of stress on brain structure continues to deepen with the development of neuroimaging, including amygdala, hippocampus, medial prefrontal lobe (including anterior cingulate gyrus), and the composition of the three stress-related intracerebral circuits. Hippocampus is thought to be associated with speech-reporting memory. Many studies have found that hippocampal volume is significantly reduced in patients with chronic PTSD. It is difficult for patients to complete tests related to speech memory. Functional magnetic resonance studies have found that PTSD patients have dorsolateral prefrontal cortex and sputum after activation of the adrenergic system. Leaf cortex, frontal cortex activity decreased and hippocampal function decreased. More severe symptoms are induced when giving PTSD patients irritating speech or images. PET, SPECT or FMRI showed decreased cerebral blood flow, decreased medial prefrontal lobe, anterior cingulate gyrus (including BA25, subgingival, BA36, BA24) [4]. Studies have found that patients with PTSD have hippocampal atrophy, decreased hippocampal function, and decreased $\mathrm{N}$-acetylaspartate. Patients with PTSD have increased amygdala activity and decreased activity in the central region of the prefrontal lobes during trauma-related activities, suggesting that symptoms of non-declarative memory impairment in PTSD patients may be associated with amygdala [5] [6] [7] [8]. Most studies have found that corticotropin-releasing hormone (CRH) is significantly elevated in patients with PTSD compared with normal people. PTSD patients may have de-suppression of CRH. Blood CRH can activate the blue-spot noradrenergic system and increase sympathetic nerves. Systemic activity, control of CRH levels may be meaningful for the treatment of high alertness symptoms 
of PTSD. Patients with PTSD have low blood cortisol levels, and patients with PTSD have hypersensitivity to small doses of dexamethasone inhibition. It is currently believed that PTSD patients may have increased sensitivity to glucocorticoid receptor (GR) and GR-mediated negative feedback. Enhanced [9] additional studies have found a sustained increase in adrenaline and norepinephrine in patients with PTSD, while blood BDNF is significantly lower than in the normal population [10]. Bracha HS et al. [11] found that apoptosis of blue spot neurons may be one of the important causes of dysfunction of blue spot in patients with PTSD. However, the above research results still have some controversy and need further discussion.

\section{Pathogenic Gene Research}

PTSD has some certain heritability, and the disease is also considered to be multi-genetic. The susceptibility of PTSD symptoms after non-war trauma is moderately inherited, and many genes affecting trauma exposure also affect the susceptibility to the symptoms of PTSD. Molecular genetics through animal studies found that PTSD may be associated with the dopamine system (DRD2, dopamine transporter gene DAT), serotonin system (serotonin transporter gene 5-HTT), glucocorticoid receptor gene (GR), gamma The aminobutyric acid (GABA) receptor gene, the apolipoprotein $\mathrm{E}$ (APOE) gene, the brain-derived neurotrophic factor (BDNF) gene and the neuropeptide Y (NPY) gene are involved.

\subsection{DRD2 and PTSD}

Dopamine is a neurotransmitter in the hypothalamus and pituitary gland, it is a chemical material used to help cells and transmit pulses, and has axonal connections and interactions with the gonadotropin-releasing hormone at the nerve endings. Ishibashi $\mathrm{K}$ et al. [12] found that the severity of PTSD was positively correlated with the level of dopamine in the urine and plasma of patients. The concentration of dopamine in the central nervous system is affected by mental factors and is mainly responsible for the lust and feeling of the brain. The midbrain dopamine system is associated with the psychomotor effects of drug addiction and the control of reward mechanisms. Literature [13] [14] reported that the midbrain dopamine system and the midbrain cortex dopamine system also play an important role in learning and memory. PTSD is to some extent a mental disorder associated with emotional memory.

A number of animal experiments suggest that dopaminergic neurons in the amygdala and other regions of the limbic system are highly sensitive to traumatic stress. The central application of dopamine agonists can reduce mortality after experimental traumatic stress in mice, and the use of dopamine receptor blockers can increase mortality after experimental traumatic stress in mice [15].

The DRD2 gene encoding the dopamine D2 receptor is located at 11q22-q23 and is $65.8 \mathrm{~kb}$ in length. It consists of 8 exons and 7 introns and encodes a pro- 
tein containing 415 amino acid residues. It belongs to the G protein coupled receptor family, DRD2 gene can form two long isoforms (D2L) and short (D2S) by alternative splicing. D2L is multi-distributed and protruded from the posterior membrane, while D2S is distributed in the presynaptic membrane [16]. Studies have shown that dopamine D2 receptors are present in the human central nervous system and gastric mucosa, but are rarely distributed on the gastric mucosa.

In human genetics research, the single nucleotide polymorphism of DRD2 gene may have three types: gene polymorphism in promoter region, gene polymorphism in coding region, and polymorphism in non-coding region. Many studies have shown that the occurrence of PTSD is related to the DRD2 gene, and research in this area has continued. A deletion/insertion mutation (-141 Cdel/ins) of one cytosine at position -141 in the promoter region is one of the most interesting sites. The $\mathrm{DRD} 2$ gene encoding the $\mathrm{D} 2$ receptor is located in the $11 \mathrm{q} 23$ region of the chromosome, and has a total length of $270 \mathrm{~kb}$, and has 8 exons. The TaqIA cleavage site exists on the $\mathrm{D} 2$ receptor gene, and the resulting TaqIA polymorphism has two alleles $\mathrm{A} 1$ and $\mathrm{A} 2$, and three genotypes $\mathrm{A} 1 / \mathrm{A} 1, \mathrm{~A} 1 / \mathrm{A} 2$, and A2/A2. Animal experiments have confirmed that dopaminergic neurons in the amygdala and other regions of the limbic system are highly sensitive to traumatic stress. The use of dopamine agonists in the central nervous system can reduce mortality after experimental traumatic stress in rats, while dopamine receptor blockers have the opposite effect [17]. Non-coding region SNPs includes TapIA, B, and C. TapIA has four alleles A1-A4. Studies have shown that individuals with A2 alleles are more likely to develop tardive dyskinesia in men with PTSD [18]. Christianne et al. [19] studied a group of PTSD patients with substance abuse and found that the higher the frequency of DRD2TapIA, the higher the incidence of PTSD. Segman et al. [20] showed that the dopamine transporter SLC6A3 (DAT1) 3' polymorphism is associated with the development of chronic PTSD.

\subsection{5-HTTLPR and PTSD}

Serotonin (5-HTT) is an important transmitter of the central nervous system, and the gene encoding 5-HTT has been shown to be closely related to various psychiatric diseases. The 5-hydroxytryptamine transporter (5-HTTLPR) plays a crucial role in the delivery of 5-HTT transmitter activity. Foreign studies on 5-HTTLPR began in the year of 1944. In 1996, Lesch reported on Science that 5-HTTLPR has a great correlation with anxiety, making polymorphism research of this gene a hot spot [21] [22] [23]. At present, more researches are on the 5-HTTLPR polymorphism related to emotion, spirit, personality disorder and personality traits. 5-HTTLPR has a $44 \mathrm{bp}$ fragment deletion or insertion. The resulting alleles are S (containing 14 repeat units) and L (containing 16 repeat units), which constitute three genotypes SS, SL, LL. Y Liu et al. [24] explored the relationship between 5-HTTLPR polymorphism and combat exposure and PTSD diagnosis. The results showed a correlation between 5-HTTLPR genotype 
and PTSD diagnosis in NHB veterans. NA Kimbrel et al. [25] explored the 186 returned Iraqi and Afghan veterans genotyped as a 5-HTTLPR polymorphism. As a result, veterans carrying the S-allele of the 5-HTTLPR polymorphism may face an increased risk of adjustment problems and a lower quality of life after deployment to the theater. The results of the RH Pietrzak et al. [26] study suggest that the low expression variant of the 5-HTTLPR polymorphism modifies the risk of PTSD.

\subsection{Other Gene-Related Findings Associated with PTSD}

1) Low expression of FKBP5mRNA may be associated with high levels of symptomatic risk of PTSD [27] [28]. 2) GABA receptor subunit $\alpha 3$ polymorphisms GABRA2 are associated with post-traumatic PTSD in children [29]. 3) Studies of patients with PTSD who have experienced war have shown that the ApoE2 allele is associated with symptoms such as memory impairment [30].

\section{Vision}

Although many advances have been achieved in the research of PTSD in recent years, there are still many problems that have not been solved, for example, the pathogenesis of PTSD caused by GA2, BA, etc., and whether PTSD neurophysiological changes and emotional stimulation are encoded, etc., which are helpful to understand the high-risk factors of PTSD, also beneficial to the early intervention and treatment of PTSD, providing new methods and ideas for future clinical practice and research.

\section{Conflicts of Interest}

The authors declare no conflicts of interest regarding the publication of this paper.

\section{References}

[1] American Psychiatric Association (1980) American Psychiatric Association Diagnostic and Statistical Manual. Washington DC.

[2] Do, L.L.T.N. (2011) American Psychiatric Association Diagnostic and Statistical Manual of Mental Disorders (DSM-IV). Encyclopedia of Child Behavior and Development. Springer, Boston, MA, 84-85..

[3] American Psychiatric Association (2013) Diagnostic and Statistical Manual of Mental Disorders (DSM-5 ${ }^{\circledR}$ ). American Psychiatric Publication.

[4] Bremner, J.D. (2007) Neuroimaging in Posttraumatic Stress Disorder and Other Stress-Related Disorders. Neuroimaging Clinics of North America, 17, 523-538. https://doi.org/10.1016/j.nic.2007.07.003

[5] Pitman, R.K., Altman, B., Greenwald, E., et al. (1991) Psychiatric Complications during Flooding Therapy for Posttraumatic Stress Disorder. The Journal of Clinical Psychiatry, 52, 17-20.

[6] Bremner, J.D., Staib, L.H., Kaloupek, D., et al. (1999) Neural Correlates of Exposure to Traumatic Pictures and Sound in Vietnam Combat Veterans with and without 
Posttraumatic Stress Disorder: A Positron Emission Tomography Study. Biological Psychiatry, 45, 806-816. https://doi.org/10.1016/S0006-3223(98)00297-2

[7] Shin, L.M., Orr, S.P., Carson, M.A., et al. (2004) Regional Cerebral Blood Flow in the Amygdala and Medial Prefrontalcortex during Traumatic Imagery in Male and Female Vietnam Veterans with PTSD. Archives of General Psychiatry, 61, 168-176. https://doi.org/10.1001/archpsyc.61.2.168

[8] Bocchio-Chiavetto, L., Miniussi, C., Zanardini, R., et al. (2008) 5-HTTLPR and BDNF Val66Met Polymorphisms and Response to rTMS Treatment in Drug Resistant Depression. Neuroscience Letters, 437, 130-134. https://doi.org/10.1016/j.neulet.2008.04.005

[9] De Kloet, C.S., Vermetten, E., Geuze, E., et al. (2007) Elevated Plasma Corticotrophin-Releasing Hormone Levels in Veterans with Posttraumatic Stress Disorder. Progress in Brain Research, 167, 287-291. https://doi.org/10.1016/S0079-6123(07)67025-3

[10] Strawn, J.R. and Geracioti Jr., TD. (2008) Noradrenergic Dysfunction and the Psychopharmacology of Posttraumatic Stress Disorder. Depression and Anxiety, 25, 260-271. https://doi.org/10.1002/da.20292

[11] Li, M., Han, F. and Shi, Y.X. (2010) Experimental Study on Apoptosis of Neurons in the Locus Nucleus of Rats with PTSD. Chinese Journal of Histochemistry and Cytochemistry, No. 1, 15-19.

[12] Ishibashi, K., Ishii, K., Oda, K., et al. (2010) Competition between 11C-Raclopride and Endogenous Dopamine in Parkinson's Disease. Nuclear Medicine Communications, 31, 159-166. https://doi.org/10.1097/MNM.0b013e328333e3cb

[13] Nikolaus, S., Antke, C., Beu, M., et al. (2010) Cortical GABA, Striatal Dopamine and Midbrain Serotonin as the Key Players in Compulsive and Anxiety Disorders-Results from in Vivo Imaging Studies. Reviews in the Neurosciences, 21, 119-140.

[14] Hien, D.A., Jiang, H., Campbell, A.N.C., et al. (2009) Do Treatment Improvements in PTSD Severity Affect Substance Use Outcomes? A Secondary Analysis from a Randomized Clinical Trial in NIDA's Clinical Trials Network. American Journal of Psychiatry, 167, 95-101.

[15] Waraczynski, M., Salemme, J. and Farral, B. (2010) Brain Stimulation Reward Is Affected by D2 Dopamine Receptor Manipulations in the Extended Amygdala but Not the Nucleus Accumbens. Behavioural Brain Research, 208, 626-635. https://doi.org/10.1016/j.bbr.2010.01.009

[16] Monakhov, M., Golimbet, V., Abramova, L., et al. (2008) Association Study of Three Polymorphisms in the Dopamine D2 Receptor Gene and Schizophrenia in the Russian Population. Schizophrenia Research, 100, 302-307.

[17] Inglis, F.M. and Moghaddam, B. (1999) Dopaminergic Innervation of the Amygdala Is Highly Responsive to Stress. Journal of Neurochemistry, 72, 1088-1094.

[18] Wei, W. and Luo, H. (2008) Study Overview on the Etiology and Pathogenesis of Tardive Dyskinesia. Youjiang Medical Journal, 36, 624-625.

[19] Esposito-Smythers, C., Spirito, A., Rizzo, C., et al. (2009) Associations of the DRD2 TaqIA Polymorphism with Impulsivity and Substance Use: Preliminary Results from a Clinical Sample of Adolescents. Pharmacology Biochemistry and Behavior, 93, 306-312. https://doi.org/10.1016/j.pbb.2009.03.012

[20] Segman, R.H., Cooper-Kazaz, R., Macciardi, F., et al. (2002) Association between the Dopamine Transporter Gene and Posttraumatic Stress Disorder. Molecular 
Psychiatry, 7, 903. https://doi.org/10.1038/sj.mp.4001085

[21] Klein, B., Mitchell, J., Gilson, K., et al. (2009) A Therapist-Assisted Internet-Based CBT Intervention for Posttraumatic Stress Disorder: Preliminary Results. Cognitive Behaviour Therapy, 38, 121-131. https://doi.org/10.1080/16506070902803483

[22] Hou, F.S., Ting, L.I., Juan, L.I., et al. (2011) The Effects of Demographic Features on Differences in Sensitivity between PCL-C and SCL-90 Scores in a Follow-Up Study in Secondary School Students in the Wenchuan Earthquake Region. Biomedical and Environmental Sciences, 24, 642-648.

[23] Wang, Z., Tang, Y. and Shi, S. (2006) Status Quo of Domestic Research on PTSD. Shanghai Archives of Psychiatry, 18, 372-374.

[24] Liu, Y., Garrett, M.E., Dennis, M.F., et al. (2015) An Examination of the Association between 5-HTTLPR, Combat Exposure, and PTSD Diagnosis among US Veterans. PLOS ONE, 10, e0119998.

[25] Kimbrel, N.A., Morissette, S.B., Meyer, E.C., et al. (2015) Effect of the 5-HTTLPR Polymorphism on Posttraumatic Stress Disorder, Depression, Anxiety, and Quality of Life among Iraq and Afghanistan Veterans. Anxiety, Stress, \& Coping, 28, 456-466. https://doi.org/10.1080/10615806.2014.973862

[26] Pietrzak, R.H., Galea, S., Southwick, S.M., et al. (2013) Examining the Relation between the Serotonin Transporter 5-HTTPLR Genotype x Trauma Exposure Interaction on a Contemporary Phenotypic Model of Posttraumatic Stress Symptomatology: A Pilot Study. Journal of Affective Disorders, 148, 123-128.

https://doi.org/10.1016/j.jad.2012.11.003

[27] Van Zuiden, M., Geuze, E., Willemen, H.L.D.M., et al. (2012) Glucocorticoid Receptor Pathway Components Predict Posttraumatic Stress Disorder Symptom Development: A Prospective Study. Biological Psychiatry, 71, 309-316. https://doi.org/10.1016/j.biopsych.2011.10.026

[28] van Zuiden, M., Kavelaars, A., Geuze, E., et al. (2013) Predicting PTSD: Pre-Existing Vulnerabilities in Glucocorticoid-Signaling and Implications for Preventive Interventions. Brain, Behavior, and Immunity, 30, 12-21.

[29] Nelson, E.C., Agrawal, A., Pergadia, M.L., et al. (2009) Association of Childhood Trauma Exposure and GABRA2 Polymorphisms with Risk of Posttraumatic Stress Disorder in Adults. Molecular Psychiatry, 14, 234. https://doi.org/10.1038/mp.2008.81

[30] Freeman, T., Roca, V., Guggenheim, F., et al. (2005) Neuropsychiatric Associations of Apolipoprotein E Alleles in Subjects with Combat-Related Posttraumatic Stress Disorder. The Journal of Neuropsychiatry and Clinical Neurosciences, 17, 541-543. https://doi.org/10.1176/jnp.17.4.541 